\title{
Working
}

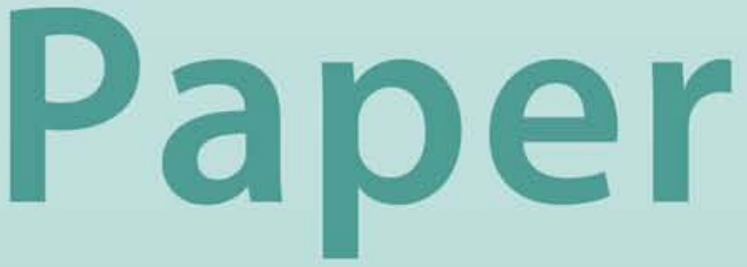


Dynamic Loan Loss Provisions in Uruguay: Properties, Shock Absorption Capacity and Simulations Using Alternative Formulas

Torsten Wezel 


\title{
IMF Working Paper
}

Monetary and Capital Markets Department

\section{Dynamic Loan Loss Provisions in Uruguay: Properties, Shock Absorption Capacity and Simulations Using Alternative Formulas}

\author{
Prepared by Torsten Wezel ${ }^{1}$
}

Authorized for distribution by Carlos Medeiros

May 2010

\begin{abstract}
This Working Paper should not be reported as representing the views of the IMF. The views expressed in this Working Paper are those of the author(s) and do not necessarily represent those of the IMF or IMF policy. Working Papers describe research in progress by the author(s) and are published to elicit comments and to further debate.

This paper assesses the merits of countercyclical loan loss provisioning in Uruguay. Using a stress test methodology, it quantifies the protection against macroeconomic shocks provided by the stock of dynamic provisions accumulated since 2001 and finds that medium-sized shocks would be fully absorbed, offsetting the additional costs caused by rising specific provisions. In addition, the paper simulates the path of dynamic provisions under the formulas used in Spain, Peru and Bolivia, showing that the alternative paths diverge significantly from the actual buildup and in part better conform to the Uruguayan credit cycle.

JEL Classification Numbers:G21, G28

Keywords: Dynamic Provisioning, Procyclicality, Latin America

Author’s E-Mail Address:twezel@imf.org

\footnotetext{
${ }^{1}$ The author wishes to thank Pablo Bazerque and Ariel Imken (Superintendencia de Instituciones de Intermediación Financiera, Uruguay) for their close collaboration in this project, as well as Michel Canta (Comisión Nacional Supervisora de Empresas y Valores, Peru) and Jesús Saurina (Banco de España) for their helpful assistance with the application of the alternative provisioning formulas. Gaston Gelos, Noel Sacasa and Francesco Columba (all IMF) kindly provided valuable comments and suggestions.
} 
CONTENTS

PAge

I. Introduction ...................................................................................................

II. The Uruguayan System of Dynamic Provisioning ……...............................................

III. The Sufficiency of Dynamic Provisions under Macroeconomic Shocks ........................ $\underline{9}$

A. Empirical Approach ..........................................................................................

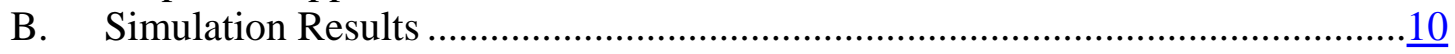

IV. Simulations Using Alternative Provisioning Formulas …………………….................11

A. Characteristics of Alternative Formulas …………………………………….....11

B. Simulation Results .......................................................................................

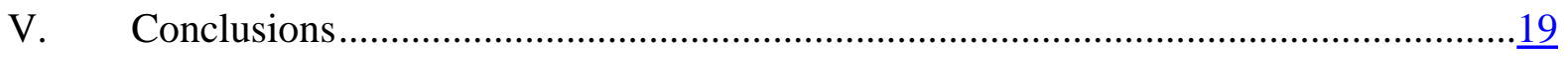

Tables

1. Set of Shocks Depleting the Stocks of Dynamic Provisions ...............................................10

2. Coverage of Expected Loan Losses under Different Stress Test Scenarios .........................11

3. Correlations Between Provisioning Flows and Changes in Credit \& Activity, 2004-09 ....118

Figures

1. Bank Loans and Dynamic Provisions .....................................................................................

2. Share of Specific and Dynamic Provisions in Total Loans ..................................................

3. Evolution of Dynamic Provisions With and Without Loan Losses .........................................

4. Effect of Dynamic Provisioning on the Return on Assets .....................................................

5. Stock of Uruguayan Dynamic Provisions Under Different Formulas ...................................16

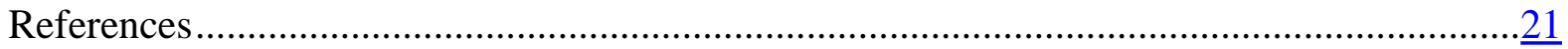




\section{INTRODUCTION}

The fallout from the global financial crisis has raised concerns about procyclicality

in banking. Procyclicality refers to the amplification of fluctuations during an otherwise normal business cycle. Among the causes of procyclicality are backward-looking loan loss provisioning rules that do not recognize the build-up of credit risks in boom phases and thus facilitate credit expansion and excessive risk-taking. Procyclical lending and provisioning occur when a period of high credit growth and lax lending standards is followed by a downturn triggering a rise in non-performing loans and, hence, specific loan loss provisions. Empirical evidence shows that credit risks build up during an upswing (Jiménez and Saurina, 2006) and that banks postpone provisioning during upswings until lending conditions deteriorate (Cavallo and Majnoni, 2001; Laeven and Majnoni, 2003). The underestimation of emerging credit risks that ultimately leads to belated recognition of loan losses coupled with tightened lending policies may then trigger a credit squeeze (Bikker and Metzemakers, 2005; Bouvatier and Lepetit, 2006). Financial institutions and their regulators alike have come to realize that the incurred loss model with its backward-looking provisioning rules does not adequately recognize the build-up of credit risks during expansionary phases and, thus, fails to provide the right incentives for prudent loan origination.

Dynamic loan loss provisioning is an instrument to mitigate procyclicality in lending and provisioning. Dynamic provisioning is one of the alternative approaches recommended by the Financial Stability Forum (2009) to recognizing and measuring loan losses that incorporate a broader range of credit information. The basic idea is to deliberately build loan loss reserves during good times that are used to absorb losses in bad times. During an economic upswing, the stock of dynamic provisions grows rapidly as loan origination is high and loan losses are typically low. The reverse is true during economic downturns, and additional provisions for actual loan losses are then covered by drawing on the stock of dynamic provisions. Specifically, banks have to build dynamic provisions in line with the estimate of long-run expected (through-the-cycle) loan losses rather than incurred losses. This is because incurred losses do not capture additional costs from future loan defaults caused by a probable deterioration in economic variables. In this context, it is not primarily the level of provisioning that matters but the timing of provisioning, as a sufficient "war chest" of loan loss reserves reduces the likelihood of failure from capital deficiency (Balla and McKenna, 2009).

The objective of dynamic provisioning is that both flows and stocks of total provisions, comprising specific and dynamic provisions, become less procyclical or even countercyclical. This is because of the explicit interaction between specific and dynamic provisions, with dynamic provisions growing when specific provisions and loan losses are lower than the through-the-cycle average and vice versa. Once the stock of dynamic provisions has reached a sufficiently high level, the monthly provisioning charges should effectively become independent of current loan losses and, if anything, 
grow in line with the rate of credit expansion. ${ }^{2}$ Hence, dynamic provisioning has a profit smoothing property. It also lessens the possibility of earnings management by curbing the effect of specific loan loss provisions on bank profits (Pérez, Salas and Saurina, 2006). For dynamic provisions to agree with international accounting standards, historical data on loan defaults are used in setting dynamic provisioning rates, although these rates ought to be broadly in line with loan losses expected for the ongoing or upcoming credit cycle.

Reaping the merits of dynamic provisioning, however, requires careful calibration. Dynamic provisioning rates need to be devised in accordance with the loan default history spanning at least a full credit cycle, in an attempt to avoid over- or underprovisioning of eventual loan losses. Imprecise estimation of the historic default rates and, consequently, miscalibration of these provisioning rates either causes an excessive burden on banks or leads to an insufficient cushion to be accessed in a downturn.

\section{Despite mandating additional provisions against new loans, dynamic provisioning cannot prevent credit booms in and of itself (Brunnermeier, Crockett, Goodhart,} Persaud and Shin, 2009). To be sure, dynamic provisioning gives incentives for banks to extend loans more carefully due to these mandatory provisions on performing loans. It is also true that the provisioning charges on new loans cause a decline in banks' capital, which for a given or desired leverage will restraint credit growth to a limited extent (Shin, 2009). However, attempting to contain a credit boom primarily through dynamic provisioning would require setting prohibitively high provisioning rates. Therefore, as provisions and capital assume complementary roles as buffers for expected and unexpected losses, respectively, capital requirements also need to become more forwardlooking, if procyclicality is to be reduced significantly.

This study contributes to the emerging literature by assessing the protection against shocks that dynamic provisions in Uruguay afford and it compares this system, using simulations, to those used in Spain, Peru and Bolivia. Similar studies by Balla and McKenna (2009) and Sacasa (2010) also use a simulation approach to ascertain how a country's loan loss provisions - in that case the United States - would have evolved under dynamic provisioning. The paper finds that the present stock of dynamic provisions would suffice to fully absorb a medium-sized shock in terms of offsetting the cost of additional specific provisions, but that it would fail to withstand a severe crisis. Moreover, simulations for the period of September 2001 to June 2009 show that the alternative dynamic provisioning formulas result in distinct accumulation paths, some of which also have desirable properties for mitigating procyclicality. Specifically, some

\footnotetext{
${ }^{2}$ For numerical examples that do not consider the impact of credit growth on provisions, see Mann and Michael (2002).
} 
formulas produce paths that have a high correlation with credit growth along the cycle and feature a markedly countercyclical buildup and drawdown of dynamic provisions.

The paper is organized as follows. Section II presents the characteristics of the Uruguayan dynamic provisioning system as well as descriptive statistics on the evolution of credit and of specific versus dynamic provisions. It also estimates the additional cost of dynamic provisioning in terms of a lower return on assets than otherwise obtained. Section III assesses whether the current stock of dynamic provisions is sufficient to provide protection against sizable economic downturns by allowing to cover rising loan delinquencies by tapping previously accumulated countercyclical provisions. To do so, the credit risk model of the central bank (Banco Central del Uruguay (BCU)) is subjected to a set of growth, exchange rate and interest rate shocks. Section IV provides simulations of the evolution of dynamic provisions on the basis of the dynamic provisioning formulas used in Spain, Peru and Bolivia and assesses the merits of each alternative system. Section V concludes and discusses a number of policy implications.

\section{The Uruguayan System of Dynamic Provisioning}

\section{Uruguay introduced dynamic loan loss provisioning in September 2001, following the Spanish model launched one year earlier. ${ }^{3}$ The regulation specifies that banks} contribute to their individual dynamic provisioning funds, $D P_{t}$, the difference between the monthly statistical net losses on loans to the non-financial private sector (NFPS) and the realized net loan loss in that month:

$$
\Delta D P_{t}=\sum_{i=1}^{5} \frac{1}{12} \beta_{i} C_{i t}-L L_{t}
$$

The statistical losses are derived by multiplying $1 / 12$ of the expected rate of loss for five loan categories, ${ }^{4} \beta_{i}$, ranging from 0.1 percent for low-risk loans to 1.8 percent for credit card loans, by the respective loan volumes, $C_{i t}$. The net loan loss, $L L_{t}$, incurred in a given period is calculated as the cost of additional specific provisions recorded in the profitand-loss statement, net of deactivations of specific provisions (i.e., reclassifications of loans toward higher categories) and recoveries of defaulted loans already written off. ${ }^{5}$ At the inception of dynamic provisioning, the beta parameters were reportedly distributed

\footnotetext{
${ }^{3}$ For details on the current provisioning system see Banco Central del Uruguay (2008).

${ }^{4}$ The five loan categories and the corresponding provisioning rates are: loans with public sector guarantees (0.1 percent); loans with other guarantees ( 0.5 percent); other loans (1.1 percent); consumer loans (1.4 percent); and credit card loans (1.8 percent).

${ }^{5}$ Contributions to the funds of dynamic provisions are recorded as expenses in the profit-and-loss statement, just like regular loan loss provisions.
} 
around the average annual loan loss during 1990-2000, which was 1 percent of loans. The dynamic provisions fund of each bank is bounded between 0 and 3 percent of total loans to be provisioned.

The countercyclical system took effect toward the end of the previous credit cycle. As a result, when the severe financial crisis of 2002/03 hit, the cushion of dynamic provisions was still insufficient to absorb a meaningful fraction of the mounting loan losses (see Figure 1). During the crisis, banks' dynamic provisions funds remained more or less depleted. With the subsequent recovery, however, the overall stock of dynamic provisions quickly approached the 3 percent limit, reaching 2.7 percent of loans to the non-financial private sector at the system level in June 2009. At more than 5 times nonperforming loans, total loan loss provisions are much higher than in other countries (see Adler et al., 2009).

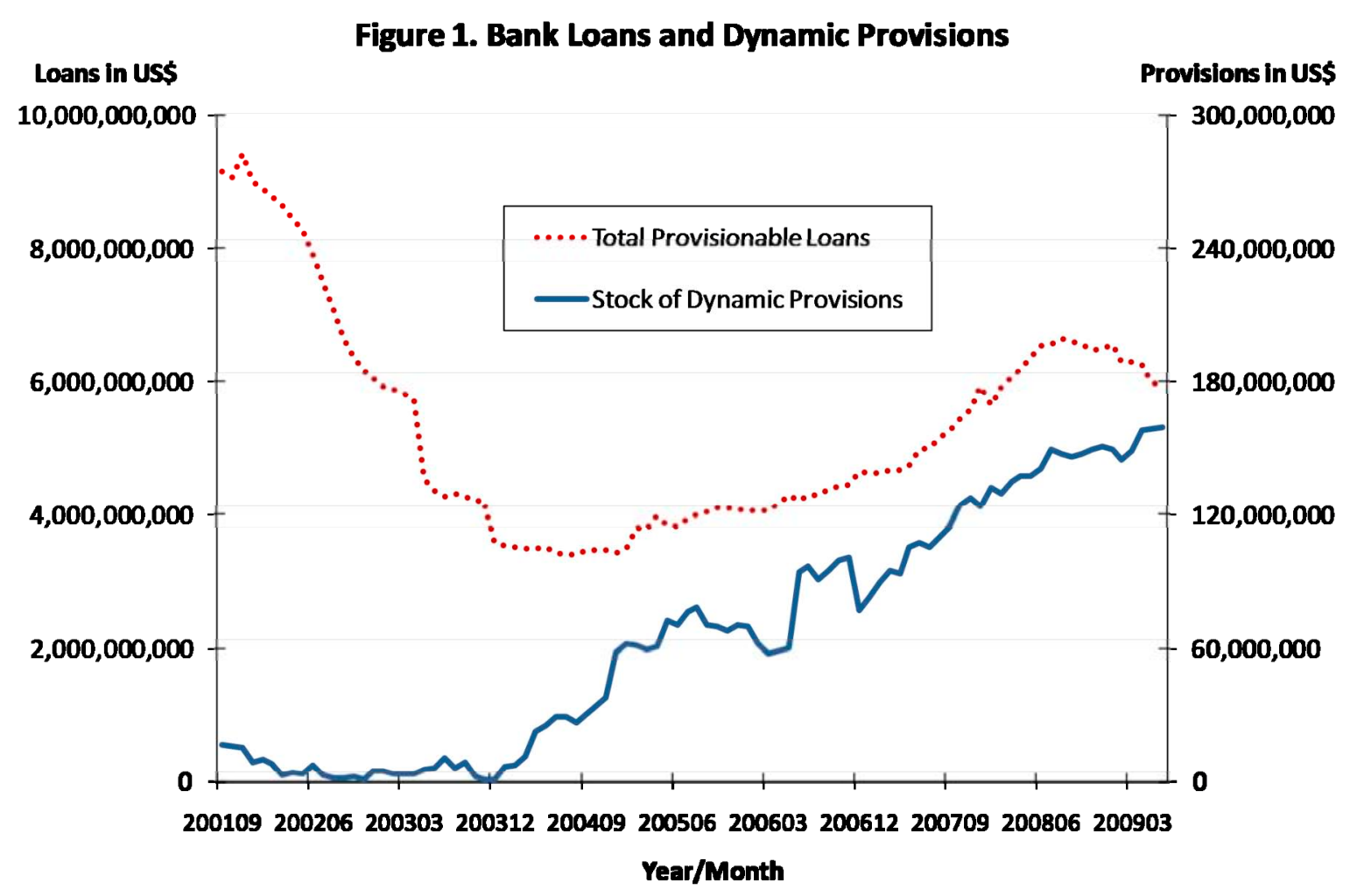

Due to the interplay between specific and dynamic provisions, overall provisions remained fairly stable in the post-crisis period. Figure 2 details the development of specific and dynamic provisions as a share of loans to the non-financial private sector (NFPS). Reclassifications of loans toward better risk categories contributed to the drop in specific provisions, initially after the crisis in 2004/05 and then again in mid-2007. Broadly constant as a share of loans, total provisions dropped thereafter when the decline in specific provisions could not be fully offset by rising dynamic provisions because banks’ dynamic provisioning funds increasingly hit the 3 percent ceiling. 
Figure 2. Share of Specific and Dynamic Provisions in Total Loans

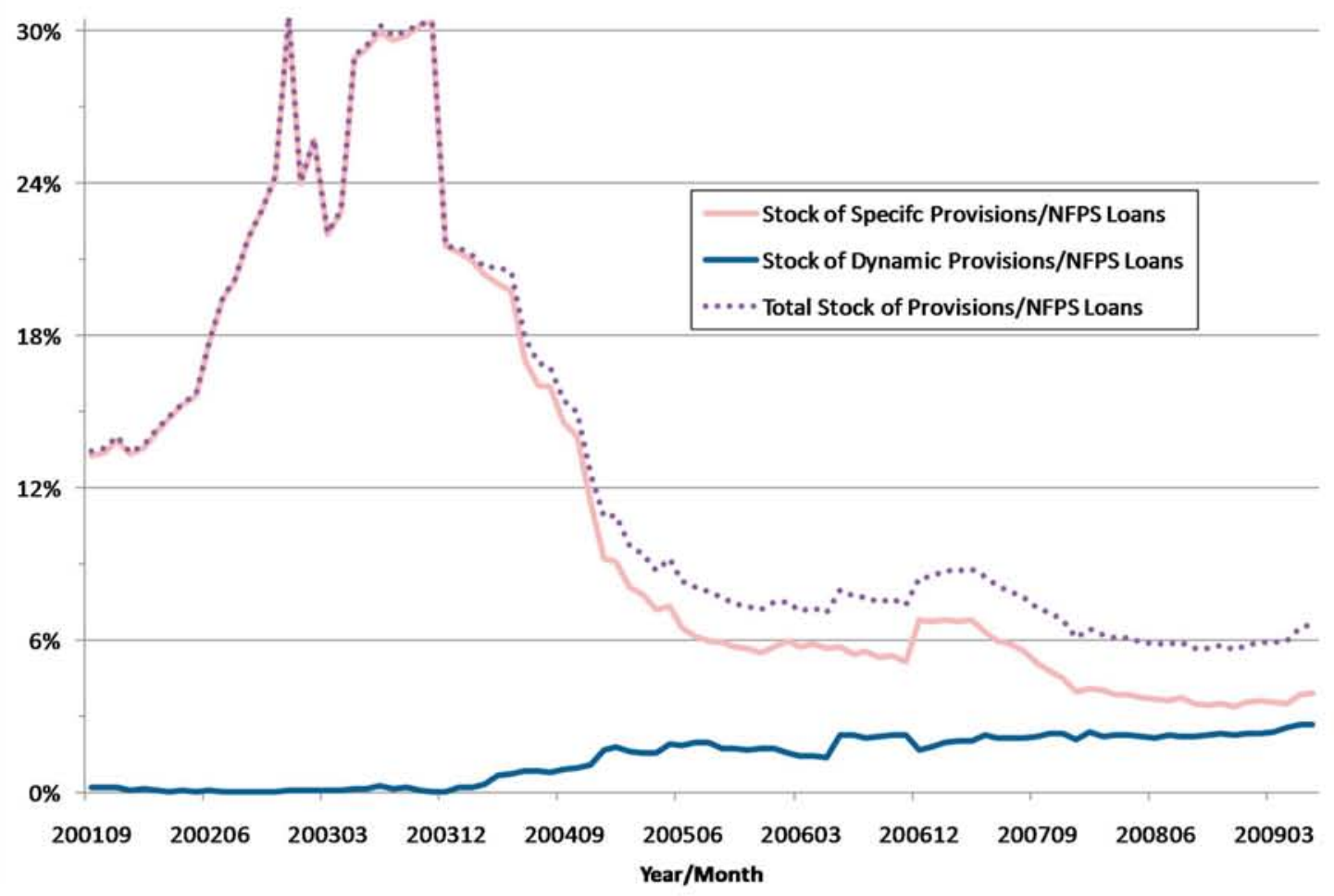

Figure 3. Evolution of Dynamic Provisions With and Without Loan Losses

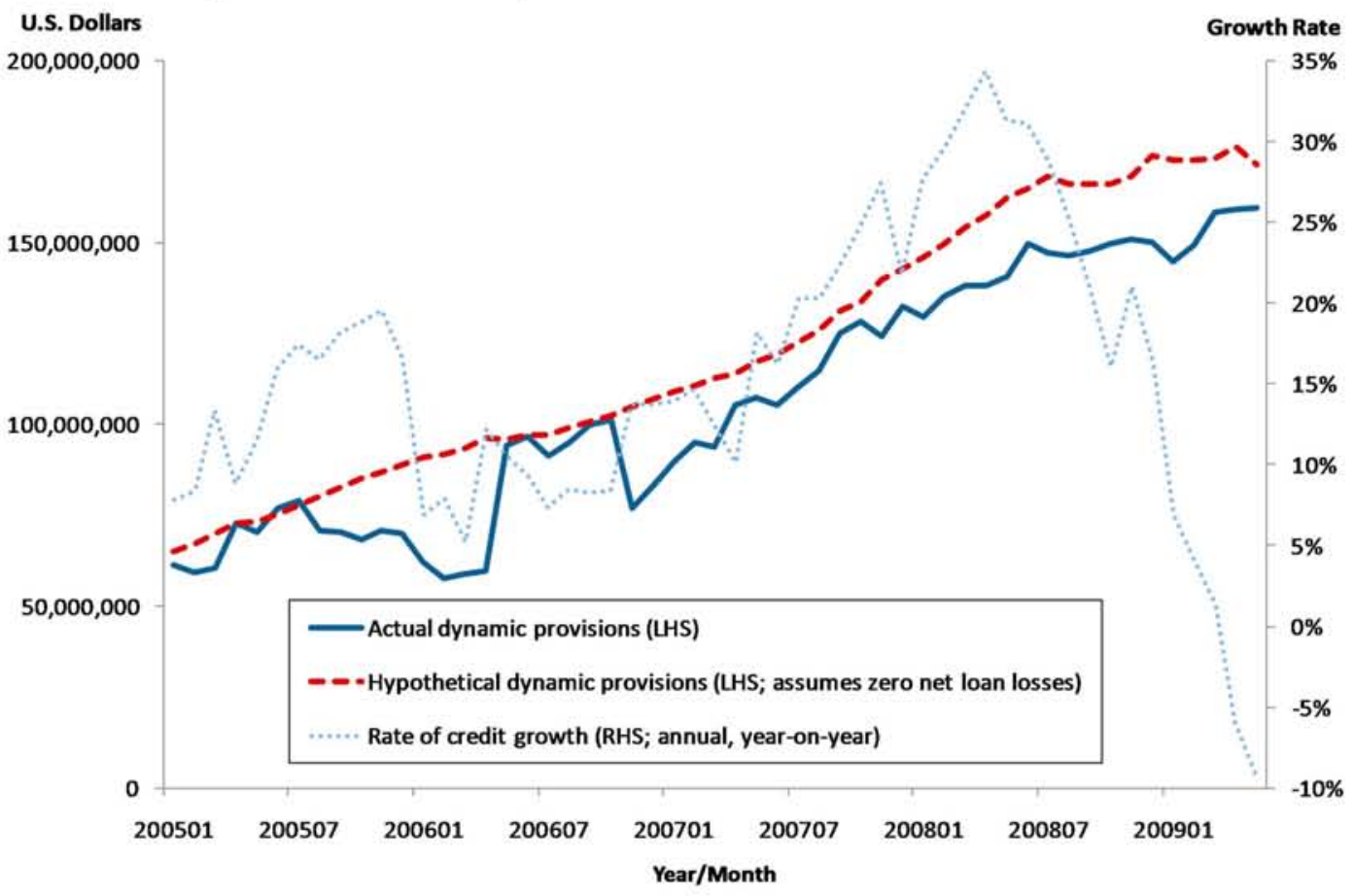


In the post-crisis period, the rapid accumulation of dynamic provisions was made possible by strong credit growth and, to some extent, the decline in impaired loans. Figure 3 depicts the evolution of dynamic provisions compared to the hypothetical case of zero loan losses since 2005, i.e. after the post-crisis catching-up in dynamic provisions. The build-up of dynamic provisions is relatively volatile during 2005-07 when fluctuations in net loan losses cause the two paths to deviate. The second factor influencing the path of dynamic provisions is the rate of credit growth depicted by the fine dotted line. Both paths of dynamic provisions react to swings in credit growth but are subject to the 3 percent ceiling that curbed the accumulation in 2008 when many banks reached that limit. The temporary pickup in credit growth from mid-2007 increases the slope of the trajectory in the hypothetical case before tapering off with the sharp decline in credit growth in 2009.

The continued accumulation of dynamic provisions in favor of financial stability has come at a cost to banks' profitability in the expansionary phase. During the 2002-03 crisis, banks could avail themselves only of the small stock of dynamic provisions that had been built up in a few months after being introduced in September 2001, while after the crisis they had to contribute a significant amount of resources to the replenishment of these provisions each year. In general terms, dynamic provisioning should only bring the recognition of losses forward in time without increasing the total buffers of specific and dynamic provisions significantly above a prudent estimate of expected losses through the cycle. This means that over the course of a normal credit cycle bank profitability should not be impaired. However, if the cycle deviates from a standard cycle, including the estimate of expected loss, or if profitability is assessed only during part of the cycle, profitability may indeed be impaired. Figure 4 illustrates the impact of dynamic provisioning on the return on average assets (RoAA) of the Uruguayan banking system.

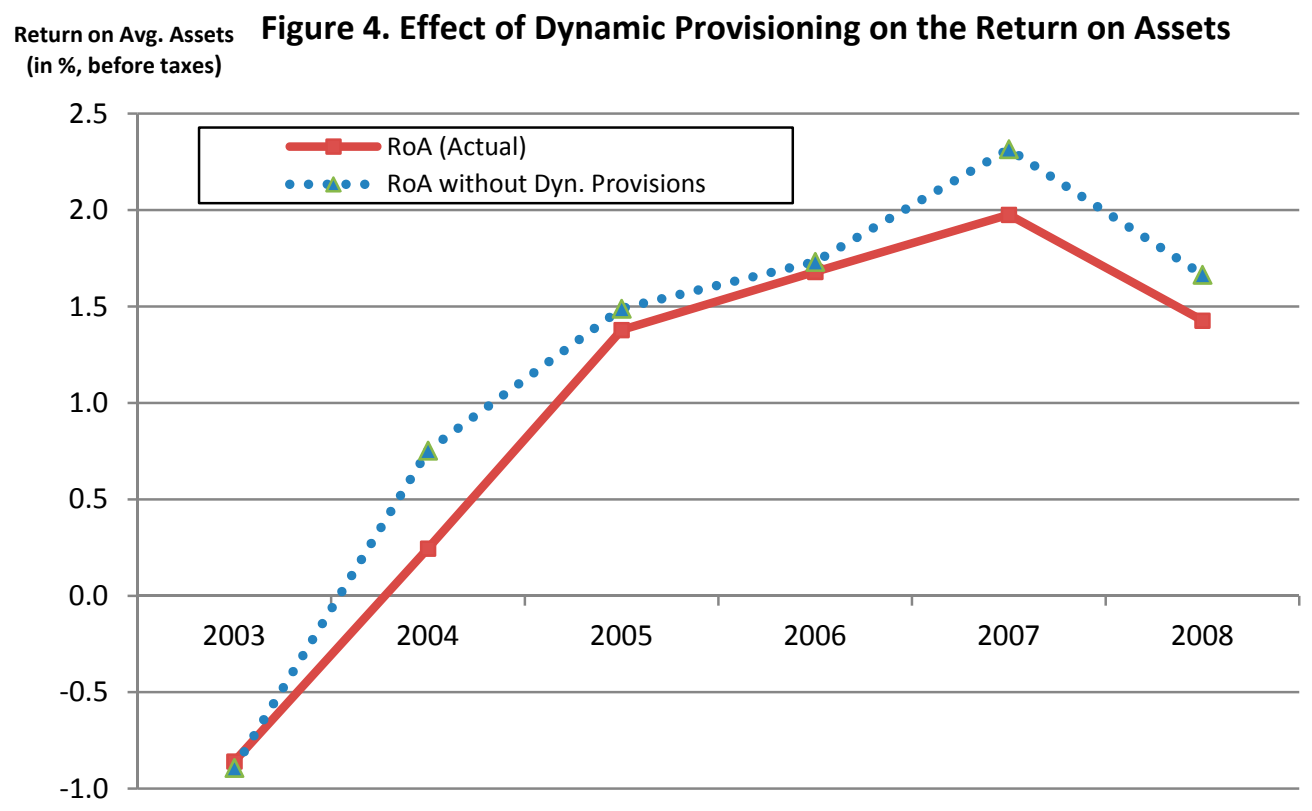


Banks' bottom line has since 2004 been consistently lower than it would have in the absence of dynamic provisioning. This is actually the intended effect of dynamic provisioning as it seeks to avoid overstating profits during an expansion which is caused by an insufficient recognition of expected losses. The two largest differences were measured for 2004 and 2007 with a hypothetical increment in the RoAA of 0.5 and 0.3 percentage points, respectively. This contrasts with a marginal benefit of merely 0.04 percentage points in 2002 and 2003, which is clearly owed to the inability to build up a sizable stock of provisions ahead of the crisis.

The apparent cost of dynamic provisioning needs to be weighed against the benefit of strengthened financial stability. As illustrated in the next section, the Uruguayan banking system can currently withstand a sizable economic shock without having to record loan-related expenses in the profit and loss statement. However, as the loan delinquencies rose only moderately during the recent downturn in 2009, so far measureable costs have arguably outweighed the rather intangible benefit of having a more resilient banking system.

\section{The Sufficiency of Dynamic Provisions under Macroeconomic Shocks}

\section{A. Empirical Approach}

Using the credit risk model of the BCU, the loan portfolios of the 13 Uruguayan banks are subjected to a set of macroeconomic shocks. These shocks were calibrated to produce default rates and consequently loan losses (assuming a fixed loss given default) that will exhaust the individual stocks of dynamic provisions in place. The BCU credit risk model has the following main input variables that historically have had an impact on expected loan losses: ${ }^{6}$ (i) the rate of GDP growth; (ii) the Uruguayan Peso-US dollar exchange rate; and (iii) the Uruguayan Bond Index (UBI). ${ }^{7}$ Different credit risk models are in place for peso and for dollar loans, and the BCU routinely applies an "adverse" scenario and a "crisis" scenario. In the present simulation, the level of additional loan losses is set such that it depletes each bank's stock of dynamic provisions. Given this level of loan losses, the model is then solved backward for the set of shocks that will produce exactly such losses.

In the exercise, two of the input variables are assumed to correlate with the third one. The variation in the exchange rate (in price quotation) is based on its historic

\footnotetext{
${ }^{6}$ In addition, the BCU credit risk model includes the unemployment rate, the level of foreign interest rates, as well as the inflation rate. For ease of optimization, these variables were kept constant in the optimization process.

${ }^{7}$ The UBI measures the spread of a portfolio containing several U.S. dollar denominated Uruguayan international bonds of different maturities with respect to comparable U.S. Treasury bond yields.
} 
correlation with GDP growth during the 2002-09 period, ${ }^{8}$ while changes in the Uruguayan Bond Index reflect its correlation with GDP growth during 2004-09. ${ }^{9}$ The correlations were found to be -0.6 for the exchange rate and +0.3 for the UBI. For example, for every ten percent increase in the negative GDP growth rate vis-a-vis the adverse scenario of the BCU (this implying a 0.37 percentage point drop), the exchange rate is set to depreciate by 6 percent (corresponding to a 0.8 percentage point change) and the bond spread to rise by 3 percent (i.e., an increase of about 20 basis points).

\section{B. Simulation Results}

\section{The simulation outcome shows that the banks could withstand a medium-sized} shock without having to bear the costs of additional specific provisions (Table 1). On average, the set of shocks that would deplete the stock of dynamic provisions consists of a 5 percent drop in economic activity, an exchange rate depreciation of about 15 percent, and a rise in the UBI to slightly above 800 basis points (250 b.p. higher than in June 2009). Having mostly attained the maximum level of their dynamic provisions funds, 85 percent of banks are, reassuringly, within one standard deviation of the magnitude of the average shock.

Table 1. Set of Shocks Depleting the Stocks of Dynamic Provisions

\begin{tabular}{ccccc}
\hline Scenario/Shock & $\begin{array}{c}\text { Change in GDP } \\
\text { in percent }\end{array}$ & $\begin{array}{c}\text { Exchange Rate Depreciation } \\
\text { in percent }\end{array}$ & $\begin{array}{c}\text { Uruguayan Bond Index } \\
\text { (basis points) }\end{array}$ & $\begin{array}{c}\text { Memorandum Item: } \\
\text { Dynamic Provisions in } \\
\text { percent of Loans* }\end{array}$ \\
\hline Average & -4.93 & 15.78 & 811 & $2.97^{\star *}$ \\
(Standard Deviation) & $(2.33)$ & $(5.01)$ & $(141)$ & $(0.81)$ \\
\hline
\end{tabular}

* As of July 2009. For technical reasons, the stock of provisions may temporarily exceed the 3 percent limit.

** Unweighted arithmetric average of individual provisioning ratios. The overall (weighted) average is 2.68 percent.

\section{Applying in addition the BCU's standard stress test scenarios illustrates that full} coverage of loan losses by dynamic provisions is ensured only under the weaker set of shocks (Table 2). While banks' dynamic provisions would more than cover the additional loan losses predicted by the adverse scenario, the rate of coverage in the BCU crisis scenario assuming a drop in GDP of 8 percent and a depreciation of over 30 percent is only 41 percent. Under an even more severe shock corresponding to changes

\footnotetext{
${ }^{8}$ Arguably, the negative correlation could be higher in a crisis, as was the case in the run-up to the 2002-03 crisis, with the correlation between changes in GDP growth and the exchange rate close to -1 . However, in view of the more resilient economy today, a lower assumed correlation appears justifiable. To be sure, during the slowdown of 2008-09, the correlation was only -0.3 .

${ }^{9}$ Basing the variation on the correlation between GDP and the Bond Index for 2002-09 (-0.6) would introduce extreme dynamics in the model. The assumed rate of correlation of -0.3 corresponds to the historic correlation found for the post-crisis period (2004-09).
} 
experienced during the 2002-03 financial crisis the coverage ratio drops to a mere 13 percent.

Table 2. Coverage of Expected Loan Losses under Different Stress Test Scenarios

\begin{tabular}{|c|c|c|c|c|c|c|}
\hline Scenario/Shocks & $\Delta \mathrm{GDP}$ & $\begin{array}{c}\Delta \text { Exchange } \\
\text { Rate* }^{\star}\end{array}$ & $\begin{array}{c}\text { Bond } \\
\text { Spread }^{\star \star}\end{array}$ & $\begin{array}{c}\text { Dynamic } \\
\text { Provisions }^{\dagger}\end{array}$ & $\begin{array}{l}\text { Expected } \\
\text { Loan } \\
\text { Losses }^{\dagger}\end{array}$ & $\begin{array}{c}\text { Coverage } \\
\text { of Losses by } \\
\text { Dyn. Prov. }\end{array}$ \\
\hline BCU adverse scenario & $-3.64 \%$ & $+13.02 \%$ & 733 & 158.8 & 100.0 & $100.0 \%$ \\
\hline $\mathrm{BCU}$ crisis scenario & $-8.00 \%$ & $+31.70 \%$ & 1000 & 158.8 & 383.6 & $41.4 \%$ \\
\hline Crisis of $2002 / 03$ & $-11.00 \%$ & $+50.00 \%$ & 2000 & 158.8 & $1,246.6$ & $12.7 \%$ \\
\hline
\end{tabular}

* Increase = depreciation of the local currency; ${ }^{*}$ Uruguayan Bond Index; † millions of US dollars

Nonetheless, in view of Uruguay's relatively favorable performance during the current global economic crisis (only one quarter of moderately negative GDP growth), the cushion afforded by the stock of dynamic provisions can be regarded as comfortable.

As the non-negligible standard deviations in table 1 indicate, a number of banks would experience either a higher- or lower-than-average coverage of losses. This reflects banks' diverging risk profiles in lending operations. An obvious way to accommodate such differing exposures would be to allow for bank-specific dynamic provisioning rates (Martínez et al., 2005). This approach would help overcome the problem whereby the current system with uniform rates tends to penalize the more efficient banks which have above-average loan growth (Panetta et al., 2009). However, a bank-specific system would require a sufficiently accurate estimate of through-the-cycle loan losses for each financial institution as well as recalibrations whenever the associated risk profile noticeably changes.

\section{Simulations Using Alternative Provisioning Formulas}

\section{A. Characteristics of Alternative Formulas}

The size of the dynamic provision funds has for years converged toward the regulatory limit of 3 percent, reaching 2.7 percent at the system level in June 2009 (see Chart 1). However, the basic idea of dynamic provisioning is that the stock of such provisions should diminish during an economic slowdown associated with stagnant or falling credit. In early 2009, when the growth rate of both GDP and credit temporarily turned negative, dynamic provisions did not fall significantly. In the end, Uruguay avoided a recession, with the economy starting to grow again in the second quarter and nonperforming loans barely rising.

This section examines whether other dynamic provisioning formulas would have produced different accumulation paths. To this end, the provisioning formulas used in Spain, Peru and Bolivia that have different properties are applied to the Uruguayan data. 


\section{Spanish Formula}

\section{The Spanish formula ${ }^{10}$ —in place since July 2000—is conceptually similar to the Uruguayan in that it offsets loan delinquencies, but it has two diverging elements.}

First, the flow of specific provisions rather than the net loan loss is subtracted from the required contribution to the dynamic provisions fund. Second, an additional component captures the expected loss of new loans. Hence, the Spanish formula computes general provisions with a countercyclical component. ${ }^{11}$ Specifically, depending on the risk of the loan category, banks are required to provision between 0 and 2.5 percent of the increase in provisionable loans (the "alpha" component) in addition to the countercyclical component (the "beta" component, with rates ranging from 0 to 1.64 percent): ${ }^{12}$

$$
\Delta D P_{t}=\sum_{i=1}^{6} \alpha_{i} \Delta C_{i t}+\left(\sum_{i=1}^{6} \beta_{i} C_{i t}-\Delta S P_{t}\right)
$$

where $\Delta D P_{t}$ is the increase in this general dynamic provision (i.e. provisioning flow) to be added on a quarterly basis; $\alpha_{\mathrm{i}}$ is average estimate of the credit loss in a year neutral from a cyclical perspective for loans in risk category i; $\Delta C_{i t}$ is the change in the stock of loans of risk category $i$ in the current period; $\beta_{i}$ is the historical average rate of specific provisions for loans of category $i$ (ideally based on at least a full credit cycle); and $\Delta S P_{t}$ is the specific provision made in the current period. The Spanish features a cap of 125 percent of the latent loss ${ }^{13}$ and also a floor of 0.1 percent of loans..$^{14}$

\footnotetext{
${ }^{10}$ For a detailed description of the Spanish system, see Fernández de Lis et al. (2000) and Saurina (2009). For a numerical example using a cohort model, see Roldan and Saurina (2009).

${ }^{11}$ With Spain's adoption of International Financial Reporting Standards in 2005 (which was made compulsory by the European Union), the formulas for computing general and dynamic provisions were merged into one (Saurina, 2009).

${ }^{12}$ See Saurina (2009). The risk categories are:

1. Negligible risk—cash and public sector exposures (both loans and securities) $-\alpha=0.00 \%, \beta=0.00 \%$;

2. Low risk-mortgages with a loan-to-value ratio below 80 percent and exposures to corporations with a rating of A or above $-\alpha=0.60 \%, \beta=0.11 \%$;

3. Medium-low risk-mortgages with a loan-to-value ratio above 80 percent and other collateralized loans not previously mentioned- $\alpha=1.50 \%, \beta=0.44 \%$;

4. Medium risk — other loans, including corporate exposures that are nonrated or have a rating below $\mathrm{A}$ and exposures to small and medium-size firms $-\alpha=1.80 \%, \beta=0.65 \%$;

5. Medium-high risk-consumer durables financing $-\alpha=2.00 \%, \beta=1.10 \%$;

6. High risk—credit card exposures and overdrafts- $\alpha=2.50 \%, \beta=1.64 \%$.

${ }^{13}$ Saurina (2009). Latent loss is defined as the probability of default times the loss given default.

${ }^{14}$ See presentation at the International Accounting Standards Board (2009).
} 
To the extent that the average rate of specific provisions is properly calibrated, the beta part of the formula ought to be zero over the credit cycle, as the cyclically-induced differences between long-run and current provisions average out. Moreover, all else equal, the additional alpha component leads to a quicker build-up of dynamic provisions during an upswing but also to stronger downward pressure whenever credit growth turns negative.

To apply the Spanish formula properly, the magnitude of the expected losses during a cyclically neutral period has to be calibrated to obtain values for the alpha parameters. In the simulation, the alpha parameters were set to be 0.1 percentage points higher than the Uruguayan beta parameters which were originally determined according to evidence of a past average annual loan loss rate of 1 percent. The difference is predicated on the average annual loan loss rate of 1.1 percent recorded over the credit cycle of 2001-08. ${ }^{15}$ Further, the beta parameters had to be set according to the average annual provisioning rates during the simulation period, which, owing to the grave 2002-03 crisis, was an excessive 3.8 percent. Hence, to preserve the comparability of the formulas, the postcrisis (2004-09) average provisioning rate of 1.1 percent was used in the simulation. ${ }^{16}$

\section{Peruvian Formula}

\section{Introduced in November 2008, the Peruvian formula differs substantially from the} two aforementioned concepts. It does not feature a cumulative fund (i.e. one that is built up gradually). Further, the "procyclical" element only enters into effect if GDP growth rises above a certain threshold. ${ }^{17}$ In the non-activation period, banks maintain a stock of general provisions of between 0.7 and 1.0 percent of loans (again, depending on the risk category of loans), to which between 0.3 and 1.5 percent of loans is added during the activation period. Once the procyclical component is deactivated again during an economic slowdown, banks are allowed to offset rising specific provisions against the stock of general provisions until the level of provisions prescribed for the non-activation period is reached again.

\footnotetext{
${ }^{15}$ The Spanish formula prescribes to take the rate of loan loss in a cyclically neutral year, which would be 2007 when the output gap closed. However, due to high loan recoveries, the loan loss rate in that year was actually negative (-0.5 percent). Thus, we deviate from the Spanish methodology and take the average loss rate over the cycle.

${ }^{16}$ In the simulation, the alpha and beta parameters were set to 0.1 percent for A-loans with liquid guarantees, 0.7 percent for other guaranteed loans, 1.6 percent for consumer loans, 2.0 percent for credit card loans, and 1.3 percent for all other loans.

${ }^{17}$ The procyclical component is activated [deactivated], if either the average annualized rate of GDP growth has been above [below] 5 percent in the past 30 months or the average change in GDP growth has been greater than 2 percent [-4 percent] in the past 12 months. For more details, see Superintendencia de Banca, Seguros y AFP Peru (2008).
} 
In the simulation, the activation period is found to begin in October 2003, after a 2.8 percent increase in GDP over the previous four quarters. ${ }^{18}$ By regulation, the required additional provisions during the activation period are phased in over six months. The surcharges used by the Peruvian formula during the activation period are applied to the Uruguayan beta parameters. These are 1 percent for consumer loans, 1.5 percent for credit card loans, and 0.5 percent for other non-guaranteed loans.

\section{Bolivian Formula}

The Bolivian formula that was enacted in December 2008 prescribes a general provision on prime quality loans which can be drawn upon fully during a slowdown. Depending on the type of loan, Bolivian banks have to maintain a dynamic provision of between 1.5 and 5.5 percent of loans. ${ }^{19}$ During a contraction, banks can access that stock to offset up to half of the additional specific provisions required in a given month, provided that the loan quality has deteriorated for six consecutive months (and the dynamic provision has been phased in fully). This deterioration is measured using the product of the share of a certain loan category in total loans and the respective actual provisioning rate, summed over all categories. ${ }^{20}$ Conversely, banks must replenish dynamic provisions when the six-month moving average of this indicator improves, then adding each month 2.78 percent of the total required provision over 36 months. ${ }^{21}$ Applied to the Uruguayan data, the access period is found to begin in July 2002 and end six months later.

Absent a full breakdown by loan type and classification for Uruguay, a number of assumptions were necessary to make the Bolivian system operational. The approach

\footnotetext{
${ }^{18}$ The assumed procyclical phase would have come to an end in the third quarter of 2009 given that the average GDP growth rate in Uruguay had already fallen by 3.8 percent during the 12 months ending in June 2009.

${ }^{19}$ The rates of the countercyclical provisions were set as follows, mortgage loans: 1.5 percent; microfinance loans: 1.6 percent; consumer loans: 2.3 percent; and prime corporate loans: 2.3 percent (for lower-category corporate loans between 3.2 and 5.5 percent).

${ }^{20}$ Formally:$$
R P R=\sum_{k=A}^{H} \alpha_{k} C_{k}
$$

where $\alpha$ is the actual rate of specific provisions applied to each loan category $\mathrm{k}$, and $C$ is the share of loan category $\mathrm{k}$ in total loans, with the loan category $\mathrm{k}$ ranging from $\mathrm{A}$ (performing loans) to $\mathrm{H}$ (defaulted loans) and encompassing three intermediate categories only applicable to corporate loans.

${ }^{21}$ At inception in December 2008, banks were required to phase in the full amount of countercyclical provisions within only 27 months (Superintendencia de Bancos y Entidades Financieras Bolivia, 2008). 
involved assigning the average of the provisioning rates for mortgage loans and prime corporate loans, which is 1.9 percent, to the category labeled "other loans", and 2.3 percent to consumer and credit card loans (omitting the other two categories of loans with guarantees). Moreover, the Bolivian loan quality indicator was proxied by the share of overall specific provisions in total loans. Note that the absolute provisioning amounts derived by this approximation are inadvertently imprecise, but the emphasis of this simulation is on obtaining the path of dynamic provisions that each formula entails.

\section{Other Formulas}

\section{In addition to the aforementioned formula, a hybrid version of the Uruguayan and} Spanish formula is applied. In this combined formula the additional alpha component of the Spanish formula is added to the Uruguayan methodology. The objective of this hybrid version is to ascertain how much additional dynamics in the stock of dynamic provisions the alpha part contributes. ${ }^{22}$

\section{Another formula is being used in Colombia, but due its data requirements it is not applied in this study. The Colombian dynamic provisioning system phased in during} $2007-08^{23}$ deviates from the other concepts by utilizing specific provisions. This system is arguably the most complex countercyclical concept currently applied, as it attaches empirically-derived probabilities of default to each of the loan classification categories, both to grade and type of loan (see Superintendencia Financiera de Colombia (SFC), 2007). The countercyclical provision consists in the difference between two rates for specific provisions which are derived from two different transition matrices (reportedly, one matrix based on through-the-cycle default probabilities and the other one based on more recent data). ${ }^{24}$ The SFC, considering the cyclical position, decides each year which of these two matrices is to be applied. While in a good year the higher rate applies, possibly forcing banks to increase provisions, the exact same difference applies conversely during a slowdown, allowing banks to tap their stock of dynamic provisions until the floor implied by the lower rate is reached. For the purpose of this study, however, the Colombian system cannot be applied as neither the individual probabilities of default based on transition matrices nor the necessary breakdown of loan data are readily available for Uruguay.

\footnotetext{
${ }^{22}$ The rule of a 3 percent limit to the stock of dynamic provisions is relaxed for the hybrid system to illustrate the effect that the additional alpha term has during periods of fast or slow credit growth.

${ }^{23}$ The countercyclical provisions for commercial loans entered into effect in July 2007, while those on consumer loans have been applied only from July 2008.

${ }^{24}$ As a numerical example, in a good year, the countercyclical provision for an "A"-rated commercial loan (net of guarantees and the expected recovery value) would be the difference between the higher rate (“provisión total individual”: 4.98 percent) and the lower rate ("provisión individual”: 1.17 percent).
} 


\section{B. Simulation Results}

Imposing the properties of the three alternative formulas yields distinctive paths for the stock of Uruguay's dynamic provisions. As Figure 5 illustrates, the various paths coincide with the Uruguayan credit cycle as implied by the line depicting the upper limit to the stock of dynamic provisions. Even so, the trajectories do exhibit greatly diverging slopes both during the crisis and the recovery phase. Indeed, some of the formulas yield a relatively smooth development of provisions over time (Peruvian and Bolivian formulas), whereas the others command a more volatile response (Spanish and Uruguayan formulas).

Figure 5. Stock of Uruguayan Dynamic Provisions under Different Formulas

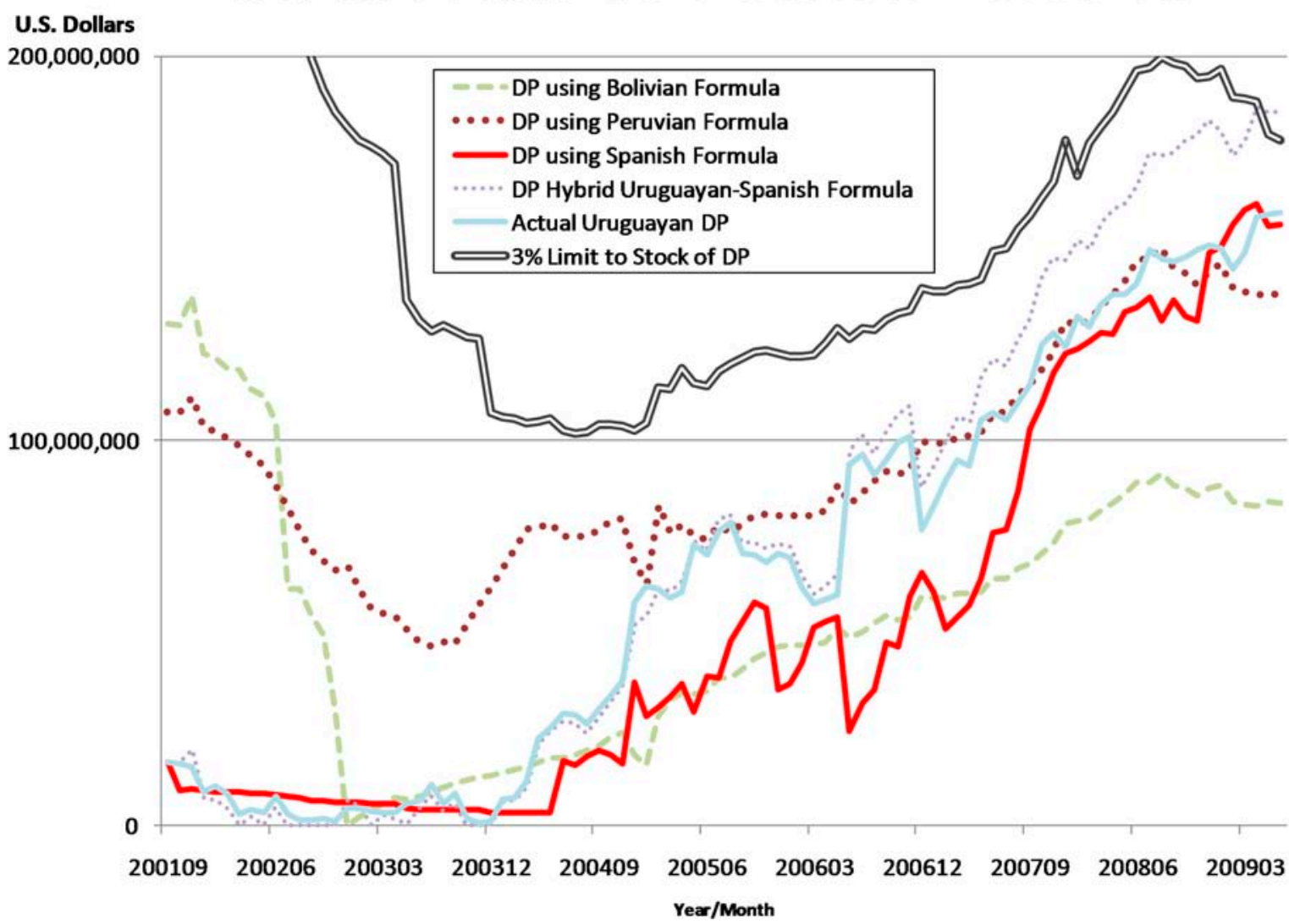

- $\quad$ Application of the Spanish formula produces a broadly similar path of dynamic provisions. ${ }^{25}$ Like the Uruguayan system, the Spanish formula would not be able to prevent a rapid drawdown on the dynamic provisions during the 2002-03 crisis. The overall stock never reaches zero, though, because of the Spanish system's

\footnotetext{
${ }^{25}$ For comparability, it is assumed that the regulatory Uruguayan limit of 3 percent of loans rather than the Spanish cap of 125 percent of the latent loss applies.
} 
unique floor of 0.1 percent of loans. During 2005-07, the Spanish formula causes the imputed stock to rise less than the actual Uruguayan stock because it does not incorporate the sizable recoveries of charged-off loans which mitigate the loan losses under the Uruguayan formula. From mid-2007, the path under the Spanish system recovers to the actual one due to lower loan recoveries and, importantly, stronger credit growth that spurs dynamic provisioning through the additional alpha component explicitly requiring to make provisions on the incremental credit.

- $\quad$ The Peruvian formula yields a smoother path than the previous two methods since it abstains from subtracting net loan losses or changes in specific provisions. The stock of provisions begins to rise in October 2003 when the procyclical component is phased in, and it afterward traces the actual Uruguayan provisions closely. The latter is a coincidence because the additional contribution due to the higher beta parameters is offset by the absence of a fall in specific provisions from 2005 (an element which is not incorporated in the Peruvian formula). Note also that the Peruvian formula is unique in that the embedded property of a general provision effectively sets a floor that cannot be undercut even in the deep crisis of 2002-03. This feature ensures that the stock of dynamic provisions is never fully depleted (or almost exhausted as under the Spanish system).

- $\quad$ The Bolivian formula implies a path similar to the Peruvian case but allows for faster access to the stock of dynamic provisions. For illustration of the impact that the access rule has, it is assumed that the countercyclical provisions are already fully constituted at the start of the sample period. Application of this access rule shows that banks can use accrued dynamic provisions from July to December 2002. As the downturn in the Uruguayan banking sector was severe and banks under the Bolivian formula can cover as much as half of the increase in specific provisions, ${ }^{26}$ the stock of countercyclical provisions quickly declines and is depleted within 6 months. Thanks to the phasing-in of dynamic provisions in the reconstitution phase, the ensuing build-up is gradual and also less volatile than under the Spanish and Uruguayan formulas, since banks cannot subtract the excess of specific provisions or loan losses over required dynamic provisions.

- $\quad$ Lastly, the hybrid Uruguayan-Spanish system makes the stock of provisions rise faster in times of high credit growth (as does the Spanish formula), while the stock also falls more quickly when credit diminishes, as was the case in early 2009 (this can be inferred from a slightly declining distance between the two lines after the peak in December 2008).

\footnotetext{
${ }^{26}$ Accessing the accumulated dynamic provisions does, however, require a "no objection" by the Bolivian Superintendency (see Superintendencia de Bancos y Entidades Financieras Bolivia, 2008).
} 


\section{The following table provides summary statistics that shed light on how each formula conforms to the quantitative objectives of dynamic provisioning.}

Table 3. Correlations Between Provisioning Flows and Changes in Credit \& Activity, 2004-09

\begin{tabular}{|c|c|c|c|c|c|}
\hline Correlation between flow variables: & $\begin{array}{l}\text { Bolivian } \\
\text { Formula }\end{array}$ & $\begin{array}{c}\text { Peruvian } \\
\text { Formula } \\
\end{array}$ & $\begin{array}{l}\text { Spanish } \\
\text { Formula }\end{array}$ & $\begin{array}{c}\text { Hybrid } \\
\text { Formula } \\
\end{array}$ & $\begin{array}{c}\text { Uruguayan } \\
\text { Formula }\end{array}$ \\
\hline Dynamic Provisions/Credit Growth & 0.46 & 0.50 & 0.32 & 0.17 & -0.07 \\
\hline Dynamic Provisions/Change in Economic Activity* & 0.28 & 0.25 & -0.09 & 0.14 & 0.09 \\
\hline Total Provisions/Credit Growth & -0.01 & 0.10 & 0.57 & -0.05 & -0.16 \\
\hline Dynamic Provisions/Specific Provisions & -0.04 & -0.04 & -0.96 & 0.08 & 0.12 \\
\hline \multicolumn{6}{|l|}{ Memorandum item: } \\
\hline Standard Deviation, Flows of Dyn. Prov. (US\$ mn.) & 2.5 & 4.2 & 8.0 & 6.9 & 7.3 \\
\hline
\end{tabular}

- $\quad$ The flow of dynamic provisions should be in line with credit growth (i.e., changes in the credit stock). In the five years starting in July 2004 (when the provisioning funds under each of the formulas resume accumulation), this is the case for results under the Bolivian and Peruvian formulas, with the correlation coefficient at 0.5, and to a lesser extent, under the Spanish formula (0.3). By contrast, the correlation for the Uruguayan formula (and the hybrid Uruguayan-Spanish formula) is close to zero. This is explained in part by the netting of recoveries of defaulted loans in the Uruguayan formula, but also by the missing alpha term that under the Spanish formula makes dynamic provisions grow faster. Similarly, the correlation with economic activity is found to be positive but generally weaker because credit growth outpaced economic activity in the post-crisis years. ${ }^{27}$

- $\quad$ Total provisions, on the other hand, need not be correlated with credit growth through the cycle but can be during an upswing. There is no notable correlation for any formula but the Spanish one which shows a highly positive linkage. The divergence is owed to the fact that the Spanish formula produces by construction a highly negative correlation between dynamic and specific provisions.

- A negative correlation between dynamic and specific provisions is desirable because it smoothes total provisions - as is shown for the Spanish formula - by counterbalancing swings in specific provisions with opposite changes in dynamic provisions. For the other formulas, the correlation between the two types of provisions is near zero. While not unexpected for the Bolivian and Peruvian formulas that lack a beta component, a near-zero correlation between the two provisions in the Uruguayan case is rather surprising and only explained by the impact of subtracting loan recoveries from the dynamic provisioning requirement.

\footnotetext{
${ }^{27}$ Using lags of the index of economic activity instead of the contemporaneous values does not significantly change the correlation coefficients nor their signs.
} 
The simulation outcome permits a number of inferences. Along the cycle, the accumulation paths of the alternative formulas broadly correspond to the actual path. However, due to netting loan recoveries, the Uruguayan formula yields a path that is somewhat less volatile than under the Spanish formula but more so than under the Bolivian and Peruvian formulas (see standard deviations of provisioning flows in Table 3). These two systems guarantee a gradual build-up and relatively low volatility of dynamic provisions but they are not responsive to swings in specific loan loss provisions. The Peruvian formula tends to produce larger stocks through the cycle than the other systems because it is the only one that prescribes a sizable minimum level of general provisions at all times. Moreover, to the extent that high credit growth is a precursor of emerging credit distress, the additional alpha component of the Spanish formula explicitly linking general provisions to new loans is justified. This point is illustrated by a faster buildup and drawdown of dynamic provisions that the Spanish and the hybrid system produce along the credit cycle as well as their higher correlation with credit growth.

\section{CONCLUSIONS}

This paper analyses the coverage provided by Uruguay's dynamic provisions and finds that the current stock would cushion a medium-sized macroeconomic shock. As the stocks of most banks are at their regulatory limit, it would take a relatively large shock for banks to experience loan losses that can no longer be covered by the dynamic provisions. Thus, in terms of safeguarding financial stability, the cushion afforded by Uruguay's dynamic provisions is arguably large enough, also keeping in mind that provisions are not designed to cover the most extreme events.

The paper also shows that alternative formulas used in Spain, Peru and Bolivia produce diverging accumulation paths. In part, the results implied by some of these alternative formulas conform better with the Uruguayan credit cycle, not least because they are more directly linked to credit growth. The paper illustrates that adding such an element to the Uruguayan formula would provide greater variability of dynamic provisions over the credit cycle.

In addition, the paper provides an estimate of the additional burden of dynamic provisioning on banks' profitability during an expansionary phase. The hypothetical return on average assets calculated in the absence of dynamic provisions exceeds the actual return by as much as half a percentage point, showing that the costs of dynamic provisions can be non-negligible in tranquil periods.

The simulations are, however, unable to answer the question whether the stocks produced by any of the formulas are adequate. Obviously, there is a tradeoff between ensuring financial stability at all times, suggesting to maintain ample provisions, and the 
efficiency of the banking system that hinges on reasonable loan loss provisions. In the case of Uruguay, the jury is still out since toward the end of the credit cycle loan delinquencies rose only slightly. That said, the question arises whether the magnitude of loan losses experienced during the 2002-03 may reoccur or whether milder shocks are to be expected thanks to Uruguay's considerable strides in modernizing its regulatory framework (see Adler, Mansilla and Wezel, 2009).

To the extent that future downturns in the banking sector are less severe than past crises, the system may be over-provisioned. For example, arbitrarily cutting the rate of loan losses during the 2002-03 crisis in half would yield an average loan loss over the cycle of 0.4 percent - below the assumed loss rate of 1 percent. This finding ties in with the assessment that the stock of dynamic provisions could withstand a sizable macroeconomic shock before failing to deny the accumulation of additional losses. However, it seems too early to reach a firm conclusion on this. In the meantime, it may be opportune to revisit the system periodically to make sure that the stock of provisions is broadly in line with potential credit risks.

Further research should aim at establishing more general results for the impact of countercyclical provisions. This could be done by applying hypothetical dynamic provisioning rules to other countries or by simulating different credit cycles to assess the properties of the various provisioning systems. Such an effort would make it possible to assess the pros and cons of adopting dynamic provisioning systems by interested supervisory authorities around the globe. It would also be in line with the ongoing work of the Basel Committee on Banking Supervision on proposals that seek to mitigate procyclicality in the financial sector, not only most prominently by strengthening capital liquidity regulations, but also by explicitly promoting forward-looking loan loss provisioning, for which dynamic provisioning is the principal tool. 


\section{REFERENCES}

Adler, G., M. Mansilla and T. Wezel, 2009, "Modernizing Bank Regulation in Support of Financial Deepening: The Case of Uruguay”, IMF Working Paper 09/199 (Washington: International Monetary Fund).

Balla, E. and A. McKenna, 2009, "Dynamic Provisioning: A Countercyclical Tool for Loan Loss Reserves”, Federal Reserve Bank of Richmond Economic Quarterly, Vol. 95, 383-418.

Banco Central del Uruguay, 2008, “Comunicación 2008/023 - Instituciones de Intermediación Financiera - Actualización N N 177 a las Normas Contables y Plan de Cuentas”, Montevideo.

Bikker, J.A. and P.A.J. Metzemakers, 2005, "Bank provisioning behaviour and procyclicality”, International Financial Markets, Institutions and Money (15), 141-157.

Bouvatier, V. and L. Lepetit, 2006, “Banks’ procyclicality behavior: does provisioning matter?”, Centre d’Economie de la Sorbonne Working Paper 2006.35

Brunnermeier, M., A. Crockett, C. Goodhart, A. Persaud, and H. Shin, 2009, “The Fundamental Principles of Financial Regulation”, (London: Centre for Economic Policy Research).

Cavallo, M. and G. Majnoni, 2001, "Do Banks Provision for Bad Loans in Good Times? Empirical Evidence and Policy Implications,” World Bank Policy Research Working Paper No. 2619 (Washington: The World Bank Group).

Fernández de Lis, S., J. Martínez Pagés and J. Saurina, 2000, “Credit Growth, Problem Loans and Credit Risk Provisioning in Spain,” Banco de España Working Paper No. 18.

Financial Stability Forum, 2009, “Report of the FSF Working Group on Provisioning”, www.financialstabilityboard.org/fsb publications

International Accounting Standards Board, 2009, “Spanish Provisions under IFRS”, Presentation at the joint IASB-FASB meeting of March 2009.

Jiménez, G. and J. Saurina, 2006, “Credit cycles, credit risk, and prudential regulation” International Journal of Central Banking (2), 65-98.

Laeven, L. and G. Majnoni, 2003, “Loan Loss Provisioning and Economic Slowdowns: Too Much, Too Late?” Journal of Financial Intermediation (12): 178-197. 
Mann, F. and I. Michael, 2002, "Dynamic Provisioning: issues and application”, Bank of England Financial Stability Review, December 2002.

Martínez, O., F. Pineda and D. Salamanca, 2005, “Esquema de Provisiones anticíclicas para Colombia”, Central Bank of Colombia, Temas de Estabilidad Financiera, July.

Panetta, F., P. Angelini, U. Albertazzi, F. Columba, W. Cornacchia, A. Di Cesare, A. Pilati, C. Salleo and G. Santini, 2009, "Financial sector pro-cyclicality - Lessons from the crisis”, Banca d'Italia Occasional Paper No. 44.

Pérez, D., V. Salas and J. Saurina, 2006, "Earning and Capital Management in Alternative Loan Loss Provision Regulatory Regimes”, Banco de España Working Paper No. 614.

Roldan, J.M. and J. Saurina, 2009, “Dynamic Provisioning in Spain”, Presentation at the IASB meeting of June 2009.

Sacasa, N., 2010, “Implementing Rules-Based Stabilizers for Banks: A Simplified Simulation for the United States 1992-2007”, IMF Working Paper, forthcoming (Washington: International Monetary Fund).

Saurina, J., 2009, “Dynamic Provisioning - The Experience of Spain,” World Bank Crisis Response Note No. 7 (Washington: The World Bank Group).

Shin, H.S., 2009, "Financial Intermediation and the Post-Crisis Financial System", Working Paper Princeton University, mimeo.

Superintendencia de Banca, Seguros y AFP Peru, 2008, “Resolución 11356 - 2008.”

Superintendencia de Bancos y Entidades Financieras Bolivia, 2008, "Modificaciones al Anexo I - Evaluación y Calificación de la Cartera de Créditos de las Directrices Generales para la Gestión del Riesgo de Crédito”, Circular No. 604/2008.

Superintendencia Financiera de Colombia, 2007, “Guia para la Implementación del Modelo de Referencia de Cartera Comercial - MRC”. 